INTERNATIONAL JOURNAL OF RESEARCHES IN BIOSCIENCES, AGRICULTURE AND TECHNOLOGY (C) VISHWASHANTI MULTIPURPOSE SOCIETY (Global Peace Multipurpose Society) R. No. MH-659/13(N) www.vmsindia.org

\title{
ULTRASONIC STUDIES OF MOLECULAR INTERACTIONS OF SOME PHENOTHIAZINES IN AQUEOUS MEDIUM AT 308K
}

\section{Usha Wasnik ${ }^{1}$ Ravi Jumle ${ }^{2}$ and P.R. Rajput ${ }^{3}$}

${ }^{1}$ Department of Chemistry, Arts Science and Commerce College, Chikhaldara, (M.S.) 444807 India. 2Department of Chemistry , Shivaji Science College, Akot, (M.S.) India

${ }^{3}$ Department of Chemistry, VBMV, Amravati, (M.S.) India us.wasnik@gmail.com

\section{Abstract:}

Ultrasonic velocity, density and viscosity have been measured experimentally in aqueous medium of Prochlorperazine maleate, Chlorpromazine hydrochloride and Tri fluoperazine dihydrochloride at $308 \mathrm{~K}$ over the entire composition range. The useful acoustic parameters namely apparent molar compressibility $\left(\phi_{\mathrm{k}}\right)$, apparent molar volume $\left(\phi_{\mathrm{v}}\right)$, adiabatic compressibility $\left(\beta_{\mathrm{s}}\right)$, specific acoustic impendence $(Z)$, intermolecular free length $\left(\mathrm{L}_{\mathrm{f}}\right)$ have been evaluated. From these parameters intermolecular interactions occurring in these solutions among the aqueous solutions have been discussed.

Keywords: Phenothiazines, ultrasonic, compressibility, behavior.

\section{Introduction:}

Ultrasonic waves, in recent years, have acquired the status of and important probe for the structure and properties of matter in basic science. Ultrasonic techniques are best suited for physicochemical studies of systems. Some of the phenomenon analyzed in recent past, are the acoustic attenuation due to phenon-phenon interaction, the nuclear spin and electron spin interaction, with the acoustic waves and phenon - electron magnetic field interaction. In the field technology, the waves are being used for electron of flaws, testing of materials, mechanical cleaning of surface etc, In medicinal science too, the waves are being used to detect bone fractures, cancer tumors, fetal conditions and in physiotherapy, bloodless surgery, cardiology, gynecology etc. Present day applications of ultrasonic are emerging in the field of forensic sciences, space research and in wars. Solute-solvent interaction is of current interest in all branches of chemistry. In various theories of liquid state, intermolecular interaction is expressed as a potential. Ultrasonic waves provide valuable information about the molecular interaction in pure liquids ${ }^{1}$, aqueous solutions ${ }^{2}$, liquid mixtures ${ }^{3}$ and also provide valuable information about the structure of solids 4 .

The study of molecular interaction in liquids provides valuable information regarding internal structure, molecular association, complex formation, internal pressure etc. The various techniques available to study them are nuclear magnetic resonance, microwave, ultraviolet and infrared spectroscopy, neutron and X-ray scattering and ultrasonic investigation. Ultrasonic technique reveals very weak intermolecular interactions due to its useful wave length range. Moreover, ultrasonic parameters are directly related to a large

number of thermodynamic parameters. Since various molecular theories of liquid state are based on thermodynamic consideration, ultrasonic absorption study and ultrasonic velocity determination provide means to study them.

Phenothiazines belongs to a class of heterocyclic compounds characterized by tricyclic aromatic ring with sulphur and nitrogen atoms and substituent in 2-and 10 - or -3- and 7-positions. Phenothiazine derivatives substituted in 2-and 10-positions 5 are commonly used as psychotropic, anticholinergic and antihistaminic drugs.

Phenothiazines are employed in pre-anesthetic medication and are a useful muscle relaxant in the treatment of tetanus. Phenothiazines are also used in veterinary therapeutics as antiparasitic slow release tablets for the treatment of animal farcioliasis, respiratory and digestive strongylosis and

Cestodiasis ${ }^{6}$.

\section{Experimental:}

Solvents methanol, dioxane and dimethyl formamide used in the present work were of AR grade and were purified and dried by the usual procedure. Densities, viscosities and ultrasonic velocities were measured at $303 \mathrm{~K}$ over a wide range of composition. Densities were determined by using bicapillarypyknometer. The viscosities were measured by precalibrated Ostwald type viscometer with an accuracy of about $\pm 0.1 \mathrm{~K}$. Ultrasonic velocity measurements were made by using an ultrasonic interferometer (Mittal Enterprises, New Delhi) at a frequency of $2 \mathrm{MHz}$ with a tolerance of $\pm 0.005 \%$. All the measurements were carried out at $303 \mathrm{~K}$. 


\section{Theory:}

Acoustic parameters such as apparent molar compressibility $\left(\phi_{\mathrm{k}}\right)$, apparent molar volume $\left(\phi_{\mathrm{v}}\right)$, adiabatic compressibility $\left(\beta_{\mathrm{s}}\right)$, specific acoustic impendence $(Z)$, intermolecular free length $\left(\mathrm{L}_{\mathrm{f}}\right)$, Limiting apparent molar volume $\left(\phi^{0} v\right)$, Limiting apparent molar compressibility $\left(\phi^{0} \mathrm{k}\right)$ were determined using following relations.
Ultrasonic velocity

Adiabatic compressibility

Apparent molar volume

Apparent molar compressibility

Intermolecular free length

Specific acoustic impendence

Limiting apparent molar volume

Limiting apparent molar compressibility

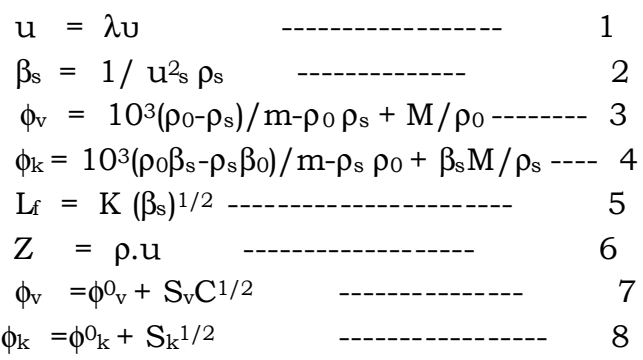

Table-1. Density, Ultrasonic Velocity and related Parameters of some phenothiazines in aqueous medium at $308 \mathrm{~K}$

\begin{tabular}{|c|c|c|c|c|c|c|c|c|c|}
\hline System & $\begin{array}{l}\text { Conc. } \\
\text { mol. } \\
\mathrm{dm}^{-3}\end{array}$ & $\begin{array}{l}\text { Density } \\
\rho \text { skm }^{-3}\end{array}$ & $\begin{array}{c}\text { Ultrasonic } \\
\text { Velocity(u) } \\
\mathrm{m} / \mathrm{s}\end{array}$ & $\begin{array}{c}\beta_{\mathrm{s} \times 10^{-10}} \\
\mathrm{~Pa}^{-1}\end{array}$ & $\begin{array}{l}\Phi v \times 10^{-5} \\
\mathrm{~m}^{3} \mathrm{~mol}^{-1}\end{array}$ & $\begin{array}{c}\Phi \mathrm{k} \times 10^{-14} \\
\mathrm{~m}^{3} \mathrm{~mol}^{-1} \\
\mathrm{~Pa}^{-1}\end{array}$ & $\begin{array}{l}\mathrm{L}_{\mathrm{f} \times} 10^{-11} \\
(\mathrm{~m})\end{array}$ & $\begin{array}{c}Z \times 10^{5} \\
\mathrm{Kg} \mathrm{m}^{-2} \\
\mathrm{sec}^{-1}\end{array}$ & $\begin{array}{c}\text { Relative } \\
\text { association } \\
\mathrm{R}_{\mathrm{A}} \mathrm{X} 10^{-3}\end{array}$ \\
\hline \multirow{5}{*}{ PCP } & 0.02 & 92.53 & 1447.5 & 4.8086 & 68.6781 & 252.3160 & 4.5973 & 14.3668 & 1014.1777 \\
\hline & 0.04 & 992.86 & 9.1 & 4.7964 & 64. & 137.2820 & 4.5914 & 14.3875 & 414 \\
\hline & 0.06 & 993.09 & 2.0 & 4.7762 & 62. & 97.5682 & 4.5817 & 14.4196 & 005 \\
\hline & 0.08 & 993.32 & & 4.7632 & 61. & 78.6137 & 4.5755 & 14. & 166 \\
\hline & 0.1 & 993.54 & 1456.2 & 4.7465 & \begin{tabular}{|l}
61.5103 \\
\end{tabular} & 66.8052 & 4.5675 & 14.4679 & 1013.1839 \\
\hline \multirow{5}{*}{ CPZ } & 0.02 & 999.13 & 1517.0 & 4.3491 & 9.89 & -7.5032 & 4.1917 & 15.1568 & 1005.08 \\
\hline & 0.04 & 999.36 & 1517.1 & 4.3476 & 22.1 & 3.3286 & 4.3713 & 15.1612 & 1005.29 \\
\hline & 0.06 & 999.56 & 1517.4 & 4.3450 & 26.3 & 6.7828 & 4.3700 & 15.1673 & 1005.43 \\
\hline & 0.08 & 999.84 & 1518.2 & 4.3392 & 28.2 & 8.0472 & 4.3671 & 15.1795 & 1005.53 \\
\hline & 0.1 & 1000.11 & 1518.9 & 4.3340 & 29.4 & 8.8654 & 4.3645 & 15.1906 & 1005.65 \\
\hline \multirow{5}{*}{ TFP } & 0.02 & 997.98 & 1531.3 & 4.2732 & 28.2304 & -37.9341 & 4.1543 & 15.2820 & 1000.79 \\
\hline & 0.04 & 998.02 & 1533.0 & 4.2636 & 38.0825 & -11.1873 & 4.1496 & 15.2996 & 1000.46 \\
\hline & 0.06 & & & 4.2294 & 40.3674 & -6.9366 & 4.1329 & 15.3660 & 848 \\
\hline & 0.08 & & & 4.2212 & 41.9771 & -1.3182 & 4.1289 & 15.3829 & 999.817 \\
\hline & 0.1 & 999.12 & 1541.6 & 4.2115 & \begin{tabular}{|l|}
42.9592 \\
\end{tabular} & 1.8835 & 4.1242 & 15.4024 & 999.701 \\
\hline
\end{tabular}

\section{Result and discussion:}

Table 1 shows that density $(\rho)$, ultrasonic velocity (u) and viscosity (n) increases with increase in concentration for all three systems. The increase in ultrasonic velocity is due to decrease in intermolecular free length $\left(\mathrm{L}_{\mathrm{f}}\right)$ as shown in table. This suggests that there is a strong interaction between chlorpromazine and solvent molecule. Adiabatic compressibility $\left(\beta_{\mathrm{s}}\right)$ is a measure of intermolecular association or repulsion calculated from the measured ultrasonic velocity $(u)$ and density $(\rho)$. Adiabatic compressibility is found to decrease with increase in concentration ${ }^{7}$. Since adiabatic compressibility is inversely related to the product of density and ultrasonic velocity based on this the compressibility is expected to decrease which has observed in the present case. When the sound waves travels through the solution, certain part of it travels through the medium and rest gets reflected by the ion 8 i.e. restriction for flow of sound velocity by the ions. The character that determines the restriction movement of sound waves is known as acoustic impendence $(Z)$. It has been found that acoustic impendence increases with increase in concentration. The apparent molar compressibility $\left(\phi_{\mathrm{k}}\right)$ explains the solute-solvent and solute- solute interactions in solution and was calculated by using the equation no.4. The apparent molar volume $\left(\phi_{\mathrm{v}}\right)$ is defined as the change in volume of solution for the added one mole of a particular component at constant temperature and pressure. It is thermodynamic property which helps in elucidating solvation behavior of electrolyte in solution. Apparent molar volume was evaluated from the density of solution and solvent.

\section{References:}

1. RP Verma and S Kumar, Ind J Pure and apply Phy 2000;312:59.

2. S Kamila, $\mathbf{S}$ jena and B Bihari. J ChemThermodyn 2005;37:820

3. R Abraham, M Abdulkhadar and CV Asokan. J ChemThermodyn 2001;32:1.

4. S Mukharjee, C Basu and US Ghosh. J Non-Cryst Solids. 1992;144:159. 
5. H. Puzanowska - Tarasiewicz, "Analytical applications of phenothiazines" in Bioactive Molecules. Vol. IV, "Phenothiazines and 1, 4Benzothiazines". R.R. Gupta, (ed); Chapter XVI, Elsevier, Amsterdam, 862 (1988).

6. Vincent and A.E Louis, Fr. Demande, 1979, P. 19, Chem. Abstr, 94, 175827 (1981).
7. Owen B.B and Kronick P K, J Phys Chem,1961; 65:81.

8. Sumathi T \& Uma Maheshwari, Indian J Pure and Applied phys., 2009; 47:782.Osmania University 2012. 